\title{
Direct electrochemistry of hemoglobin entrapped in dextran film on carbon ionic liquid electrode
}

\author{
XIAOQING LI, YAN WANG, XIAOYING SUN, TIANRONG ZHAN and WEI SUN* \\ College of Chemistry and Molecular Engineering, \\ Key Laboratory, Eco-Chemical Engineering of Ministry of Education, \\ Qingdao University of Science and Technology, Qingdao 266042, P.R. China \\ e-mail: sunwei@qust.edu.cn
}

MS received 19 September 2007; revised 23 March 2009; accepted 29 July 2009

\begin{abstract}
Direct electrochemistry of hemoglobin $(\mathrm{Hb})$ entrapped in the dextran $(\mathrm{De})$ film on the surface of a room temperature ionic liquid 1-butyl-3-methylimidazolium hexafluorophosphate $\left(\mathrm{BMIMPF}_{6}\right) \mathrm{modi}_{-}$ fied carbon paste electrode (CILE) has been investigated. UV-Vis and FT-IR spectroscopy showed that $\mathrm{Hb}$ retained its native structure in the De film. Scanning electron microscopy (SEM) indicated an uniform film was formed on the electrode surface. Cyclic voltammetric experiments indicated that the electron transfer efficiency between $\mathrm{Hb}$ and the electrode was greatly improved due to the presence of the De film and ionic liquid, which provided a biocompatible and higher conductive interface. A pair of well-defined and quasi-reversible redox peak was obtained with the anodic and cathodic peaks located at $-0 \cdot 195 \mathrm{~V}$ and $-0.355 \mathrm{~V}$ in $\mathrm{pH} 7 \cdot 0$ phosphate buffer solution, respectively. The electrochemical parameters were calculated by investigating the relationship of the peak potential with the scan rate. The fabricated $\mathrm{De} / \mathrm{Hb} /$ CILE showed good electrocatalytic ability to the reduction of $\mathrm{H}_{2} \mathrm{O}_{2}$ with the linear concentration range from $4.0 \times 10^{-6}$ to $1.5 \times 10^{-5} \mathrm{~mol} / \mathrm{L}$ and the apparent Michaelis-Menten constant $\left(K_{\mathrm{M}}{ }^{\text {app }}\right)$ for the electrocatalytic reaction was calculated as $0 \cdot 17 \mu \mathrm{M}$.
\end{abstract}

Keywords. Hemoglobin; dextran; direct electrochemistry; ionic liquid; cyclic voltammetry.

\section{Introduction}

Protein electrochemistry has gained more interests in recent years for its potential applications in biosensors and bioreactors. The mechanism of direct electron transfer (DET) between proteins and the electrode surface can also provide useful information on the structure variation, ligand binding and electron transfer process in biological system. ${ }^{1,2}$ Due to the deep burying of the electroactive prosthetic groups, the partly adsorptive denaturation of the proteins on the electrode surface or the unfavourable orientations at the electrodes, the heterogeneous electron transfer process of biomacromolecules is rather slower at the traditional electrode surface. Efforts were devoted to establish different kinds of promoters or the supporting films to facilitate the direct electron transfer between the electroactive center and the electrode surface. Different kinds of immobilized methods have been successfully ap-

*For correspondence plied to fabricate the protein modified films such as insoluble surfactants, hydrogel polymers, polyelectrolytes and nanoparticles, ${ }^{3-8}$ which provided a suitable microenvironment for the proteins to keep their native structures and gave the protein molecules more freedom in orientation. Then the direct electron transfer between the protein and the electrode surface can be easily achieved.

Room temperature ionic liquids (RTILs) have many specific physicochemical properties such as high chemical and thermal stability, relatively high ionic conductivity, negligible vapor pressure and wide electrochemical windows. ${ }^{9-11}$ RTILs have been widely used in the field of electrochemistry, ${ }^{12-15}$ organic synthesis, ${ }^{16,17}$ inorganic synthesis, ${ }^{18,19}$ liquid-liquid extraction processes ${ }^{20}$ Because of the higher ionic conductivity and wider electrochemical windows, RTILs have been used in electrochemistry and electroanalysis. ${ }^{21,22}$ Buzzeo $^{23}$ and Endres ${ }^{24}$ reviewed the recent progresses of RTILs in electrochemistry. Opallo et al investigated the ion transfer processes occurring across RTILs/aqueous solution interface 
with different electrode supports for RTIL phase such as electroactive ceramic carbon electrode, carbon nanofibres electrode or carbon ionic liquid electrode (CILE) ${ }^{25-27} \mathrm{Yu}$ et al described the formation and electrochemical application of molecular films of water-miscible imidazolium-based IL on glassy carbon electrode (GCE) ${ }^{28} \mathrm{Li}$ et al used singlewalled carbon nanotube (SWCNT) and 1-hexyl-3methylimidazolium hexafluorophosphate $\left(\mathrm{HMIMPF}_{6}\right)$ to make a gel microelectrode for studies on the electrochemical oxidation of nitric oxide. ${ }^{29}$ Sun et al fabricated a $N$-butylpyridinium hexafluorophosphate $\left(\mathrm{BPPF}_{6}\right)$ modified carbon paste electrode and investigated its electrocatalytic behaviours to ascorbic acid. ${ }^{30}$ RTILs have been used in the field of protein electrochemistry. Different kinds of RTILs composite material modified electrodes have been devised. For example, Li et al used a chitosan/BMIMPF ${ }_{6}$ for the immobilization of hemoglobin $(\mathrm{Hb})$ and investigated its electrochemical behaviours. ${ }^{31}$ Sun et al also fabricated different ionic liquid modified carbon paste electrodes and further used it as the basal electrode for the protein electrochemistry. ${ }^{32-34}$

In this paper, a $\mathrm{Hb}$ modified electrode was fabricated by using dextran (De) film and CILE. $\mathrm{Hb}$ is a commonly used heme protein, which contains two $\alpha$ and two $\beta$ subunits, each of them has an electroactive iron heme as prosthetic group. It can store and transport oxygen in muscle cells. $\mathrm{Hb}$ is often used as model for the investigation of the electron transfer reaction of heme proteins. De is a biocompatible materials and $\mathrm{Hb}$ can keep its native molecular structure in the De film. Experimental results indicated that the direct electron transfer of $\mathrm{Hb}$ was achieved and the fabricated $\mathrm{De} / \mathrm{Hb} / \mathrm{CILE}$ biosensor showed good electrocatalytic activity to the reduction of $\mathrm{H}_{2} \mathrm{O}_{2}$.

\section{Experimental}

\subsection{Reagents}

Bovine hemoglobin (Hb, MW. 64500) was purchased from Tianjin Chuanye Biochemical Limited Company. Room temperature ionic liquid 1-butyl-3methyl-imidazolium hexafluorophosphate $\left(\mathrm{BMIMPF}_{6}\right)$ was obtained from Hangzhou Kemer Chemical Limited Company. Dextran (De, average $M_{\mathrm{W}} 20000$ ) was obtained from China Guoyao Chemical Reagents Limited Company. $0 \cdot 1 \mathrm{~mol} / \mathrm{L}$ phosphate buffer solutions (PBS) with various $\mathrm{pH}$ values were prepared by mixing stock standard solutions of $\mathrm{K}_{2} \mathrm{HPO}_{4}$ with $\mathrm{KH}_{2} \mathrm{PO}_{4}$ and adjusted to the $\mathrm{pH}$ with $0.1 \mathrm{~mol} / \mathrm{L} \mathrm{H}_{3} \mathrm{PO}_{4}$ or $\mathrm{NaOH}$. All the other chemicals were of analytical reagent grade and doubly distilled water was used in all the experiments.

\subsection{Apparatus}

The electrochemical measurements were performed on a CHI 750B electrochemical workstation (Shanghai $\mathrm{CH}$ Instrumentation, China) with a conventional three-electrode system composing a $\mathrm{Hb}$ film modified CILE as working electrode, a platinum wire as auxiliary electrode and a saturated calomel electrode (SCE) as reference electrode. UV-Vis absorption spectra were recorded on a Cary 50 probe spectrophotometer (Varian Company, Australia) with the wavelength range from 300 to $650 \mathrm{~nm}$. FT-IR spectra were recorded by a Tensor 27 FT-IR spectrophotometer (Bruker Company, Germany). Scanning electron microscopy (SEM) was performed on a JSM-6700F scanning electron microscope (Japan Electron Company, Japan). The $\mathrm{pH}$ values were measured with a pHs-25 acidity meter (Shanghai Hongyi Instrument Factory, China).

\subsection{Electrode preparation}

The $\mathrm{BMIMPF}_{6}$ modified carbon paste electrode (CPE) was prepared by mixing BMIMPF $_{6}$ with graphite powder at a ratio of $25 / 75(\mathrm{w} / \mathrm{w})$ in an agate mortar. The homogeneous paste was packed into a cavity of glass tube with the diameter of $4.0 \mathrm{~mm}$. The electrical contact was obtained with a copper wire connected to the paste in the end of tube. The surface of CILE was polished by smoothing it on a weighing paper. The traditional CPE was prepared by hand-mixing of graphite powder with liquid paraffin at a ratio of $70 / 30(\mathrm{w} / \mathrm{w})$ in an agate mortar with the procedure similar to that of the CILE.

$\mathrm{The} \mathrm{Hb}$ modified CILE was prepared with the following procedure. A $10.0 \mu \mathrm{L}$, of $20.0 \mathrm{mg} / \mathrm{mL} \mathrm{Hb}$ was cast on the surface of CILE and left it to dry at room temperature. Then a $10.0 \mu \mathrm{L}$ of $6.0 \mathrm{mg} / \mathrm{mL}$ De solution (in pH 7.0 PBS) was applied on the electrode surface, which could form a stable film and fix the $\mathrm{Hb}$ tightly on the surface of electrode. A $10 \mathrm{~mL}$ beaker was covered over the electrode so that water could evaporate slowly in air and an uniform film electrode could be formed. Other modified electrodes such as De/CILE or De/Hb/CPE were prepared by same procedure. 


\subsection{Procedures}

Electrochemical experiments were performed at room temperature by using a $\mathrm{CHI} 750 \mathrm{~B}$ electrochemical workstation with cyclic voltammetry. The test solutions were deoxygenated by bubbling pure nitrogen through them for at least $15 \mathrm{~min}$. The experiments were carried out with the electrochemical cell kept in an atmosphere of pure nitrogen.

\section{Results and discussion}

\subsection{UV-Vis absorption spectra}

The positions of the Soret absorption band of heme may provide information about possible denaturation of heme protein, and particularly on conformational change in the heme group region. Therefore, UV-Vis spectroscopy is a useful tool for conformational study of heme region. ${ }^{35}$ If $\mathrm{Hb}$ is denatured, the Soret band will change or disappear. Figure 1 showed the UV-Vis absorption spectra of De and $\mathrm{Hb}$ mixture in different $\mathrm{pH}$ buffer solution. For natural $\mathrm{Hb}$ in water, the Soret band appeared at $405.7 \mathrm{~nm}$ (curve d). In $\mathrm{pH} 10.0$ and 7.0 buffer solution, the Soret band appeared at $407.0 \mathrm{~nm}$ and $405.9 \mathrm{~nm}$ (curves b and c), respectively, which was very close to that of the native $\mathrm{Hb}$. Since the difference of Soret band was less, the results suggested that $\mathrm{Hb}$ in De film was not distinctly denatured and its secondary structure was kept as the native state of $\mathrm{Hb}$.

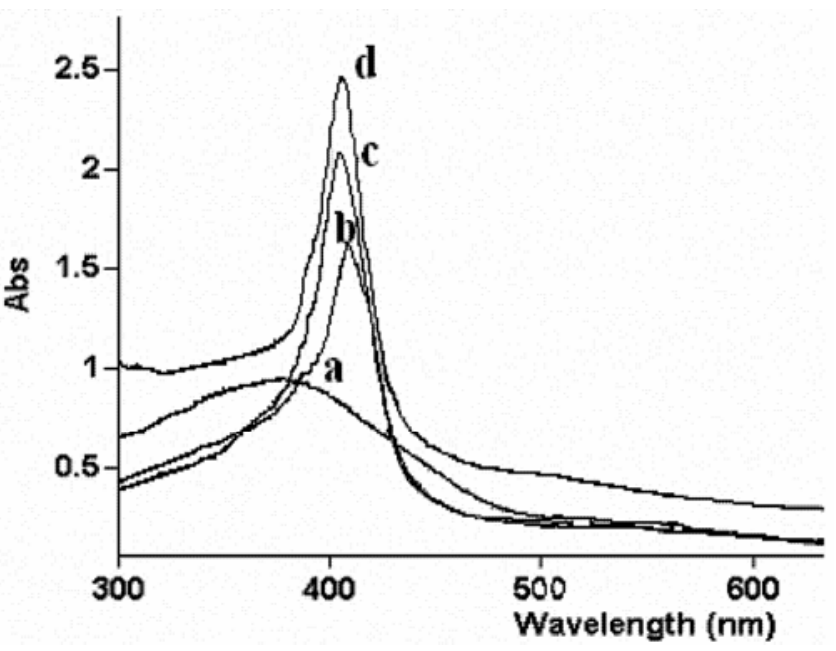

Figure 1. UV-Vis absorption spectra of $\mathrm{De} / \mathrm{Hb}$ in $\mathrm{pH}$; (a) $2 \cdot 0$; (b) $10 \cdot 0$; (c) $7 \cdot 0 \mathrm{PBS}$; (d) $\mathrm{Hb}$ in water solution, respectively.
However, when the $\mathrm{pH}$ value was changed to $2 \cdot 0$, the Soret band moved to $365.1 \mathrm{~nm}$ with the peak shape being smaller and broader (curve a), which indicated the denaturation of $\mathrm{Hb}$ in the more acidic solution. The results indicated that De might be a fine film material and $\mathrm{Hb}$ molecule in the $\mathrm{De}$ film had similar secondary structure to its native state in aqueous solution.

\section{$3.2 \quad F T-I R$ spectra}

FT-IR spectroscopy is also used to check the conformational integrity of the heme proteins. The characteristics of amide I and amide II bands of protein infrared bands provide the detailed information on the secondary structure of polypeptide chain. The amide $I$ band $\left(1700-1600 \mathrm{~cm}^{-1}\right)$ is caused by $\mathrm{C}=\mathrm{O}$ stretching vibration of peptide linkages in the backbone of protein and amide II band $\left(1620-1500 \mathrm{~cm}^{-1}\right)$ is assigned to a combination of $\mathrm{N}-\mathrm{H}$ bending and $\mathrm{C}-\mathrm{N}$ stretching vibration. ${ }^{36}$ If $\mathrm{Hb}$ is denatured, the intensities and shape of amide I and II band will diminish or even disappear. Figure 2 showed the FT-IR spectra of $\mathrm{Hb}$ in the De film. The amide I and amide II bands of $\mathrm{Hb}$ in $\mathrm{De}$ film appeared at $1654.09 \mathrm{~cm}^{-1}$ and $1539.18 \mathrm{~cm}^{-1}$ (figure $2 \mathrm{~b}$ ), which had the same position to the native state of $\mathrm{Hb}$ spec-

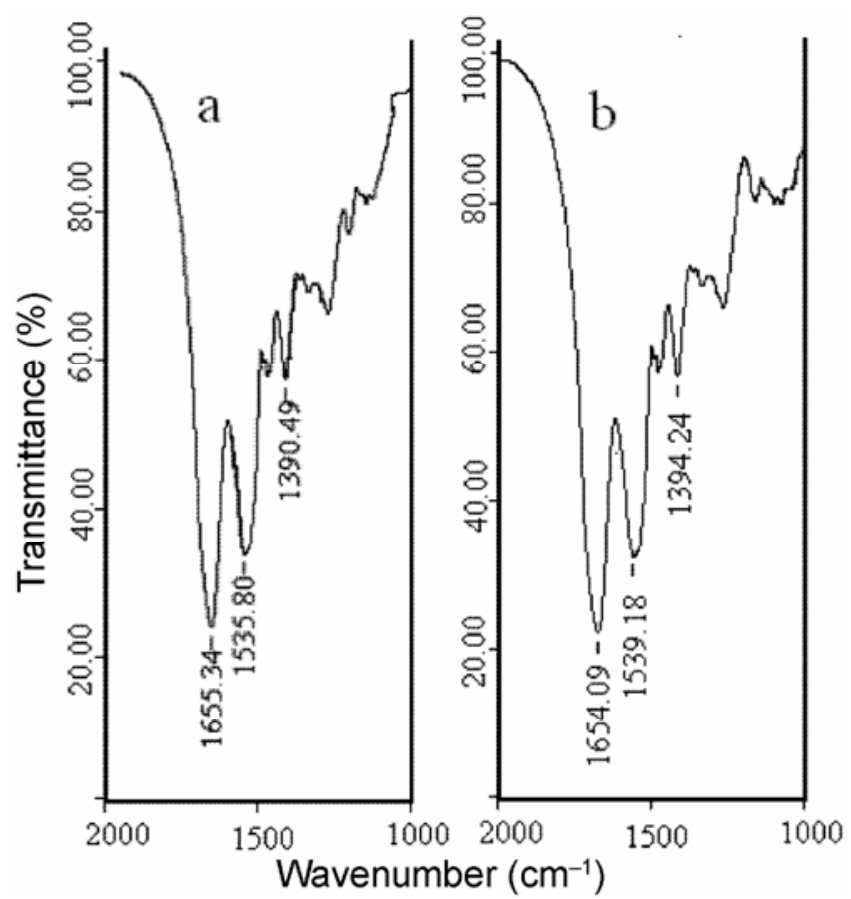

Figure 2. FT-IR spectra of the films of (a) $\mathrm{Hb}$; (b) $\mathrm{De} / \mathrm{Hb}$. 


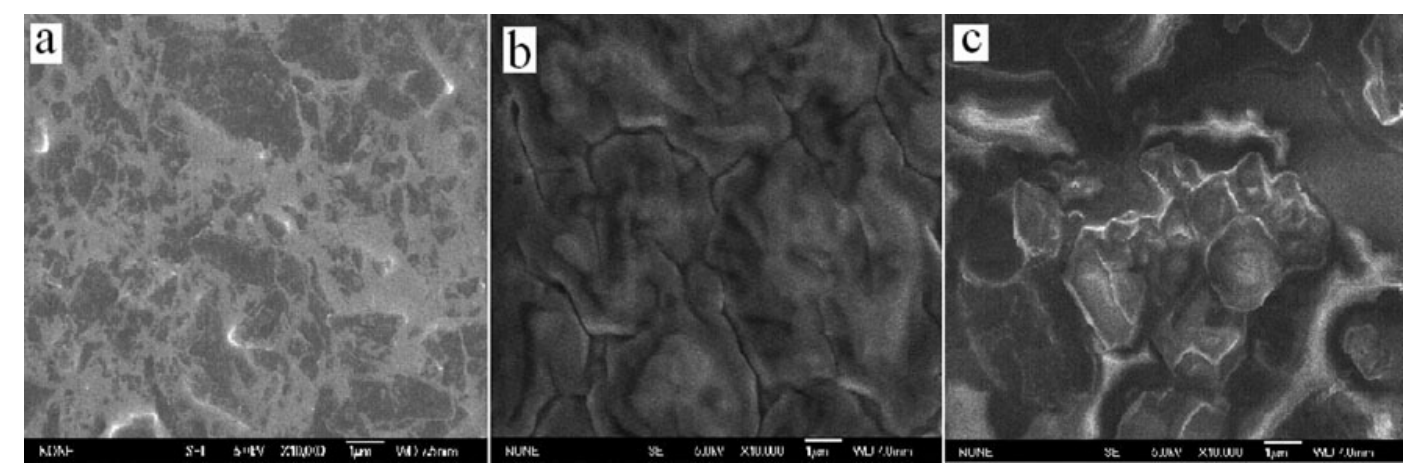

Figure 3. SEM images of (a) CILE; (b) Hb/CILE; (c) De/Hb/CILE.

trum at $1655.34 \mathrm{~cm}^{-1}$ and $1535.80 \mathrm{~cm}^{-1}$ (figure 2a). These results showed that $\mathrm{Hb}$ retained the essential features of its original structure in the De film.

\subsection{Scanning electron microscopy}

Scanning electron microscopy (SEM) was used to characterize the morphology of different kinds of modified electrodes and the results were shown in figure 3. The SEM image of CILE (figure 3a) showed a fairly uniform surface, which was due to the embedded of BMIMPF 6 between the carbon layers. As an organic ionic liquid with good solubility and high viscosity, the presence of RTIL is capable of better dispersing the graphite powder in the paste than the conventional mineral oils and bridge the carbon flakes. After $\mathrm{Hb}$ was cast on the surface of CILE, the electrode surface looked more loose and uneven with the protrusion assignable of $\mathrm{Hb}$ (figure $3 b$ ). While on the surface of the $\mathrm{De} / \mathrm{Hb} / \mathrm{CILE}$ (figure $3 \mathrm{c}$ ), an uniform film was formed, which indicated that De had good film forming ability and could interlock with $\mathrm{Hb}$ together to form a stable film.

\subsection{Direct electrochemistry}

Figure 4 showed the cyclic voltammograms of different electrodes in $\mathrm{pH}$ 7.0 PBS at the scan rate of $100 \mathrm{mV} / \mathrm{s}$. It can be seen that no redox peaks appeared on the CILE (curve a) and De/CILE (curve b). However, when the $\mathrm{Hb}$ was entrapped in the De film and modified on the surface of CILE, direct electron transfer between $\mathrm{Hb}$ and CILE was easily achieved and a pair of well-defined, quasi-reversible redox peaks were observed in the cyclic voltammogram (curve c), which was attributed to the heme $\mathrm{Fe}$ (III)/Fe (II) redox couple. For comparison, the direct electrochemistry of the $\mathrm{De} / \mathrm{Hb} / \mathrm{CPE}$ was also investigated with the cyclic voltammograms as shown in figure 5. Only a small reduction peak appeared without the oxidation peak (curve c), indicating the irreversible electrochemical process on the $\mathrm{De} / \mathrm{Hb} / \mathrm{CPE}$. Due to the presence of ILs in the carbon paste, CILE had showed some advantages such as biocompatible interface and high electron transfer rate. So the CILE played an important role in realizing the direct electron transfer with $\mathrm{Hb}$ molecules on the surface. At the same time De film is an electro-inactive substance in the potential ranges and it has good biocompatibility with polymeric network. The De film on the electrode provided suitable microenvironments to maintain the natural conformation of $\mathrm{Hb}$ and kept the bioactivity of $\mathrm{Hb}$ effectively.

From the cyclic voltammetric results the anodic (Epa) and cathodic (Epc) peak potentials were obtained as $-0.195 \mathrm{~V}$ and $-0.355 \mathrm{~V}$ (vs SCE), respectively. The apparent formal potential $\left(E^{0}\right)$, which was calculated from the equation as $E^{0 \prime}=\left(E_{\mathrm{pa}}+E_{\mathrm{pc}}\right) / 2$, was got as $-0.257 \mathrm{~V}$ and was close to the previous report. ${ }^{37}$ The peak-to-peak potential separation $\left(\Delta E_{\mathrm{p}}\right)$ at $100 \mathrm{mV} / \mathrm{s}$ was $0 \cdot 16 \mathrm{~V}$ and the ratio of redox peak current $\left(I_{\mathrm{pa}} / I_{\mathrm{pc}}\right)$ was approximately to be $1 \cdot 0$. These features also indicated that the direct electron transfer of $\mathrm{Hb}$ on the surface of CILE in the De film was achieved.

With the increase of the scan rate the redox peak currents increased gradually. In the scan rate range from 50 to $250 \mathrm{mV} / \mathrm{s}$ the peak currents increased linearly with the scan rate (figure 6), which were characteristics of surface-confined thin-layer electrochemical behaviours. So the electrochemically active $\mathrm{Hb} \mathrm{Fe}$ (III) in the film on the CILE surface was reduced to $\mathrm{Hb} \mathrm{Fe}$ (II) on the forward scan and on the reverse scan the $\mathrm{Hb} \mathrm{Fe}$ (II) produced was converted to $\mathrm{Hb} \mathrm{Fe}$ (III). 
By integration of the cathodic peak currents of cyclic voltammogram, the average surface concentration $\left(\Gamma^{*}\right)$ of electroactive species could be calculated according to the following equation:

$$
Q=n F A \Gamma^{*},
$$

where $Q$ is charge passing through the electrode with full reduction of electroactive $\mathrm{Hb}$ in the film, $n$ is the number of electron transferred, $F$ is the Fara-

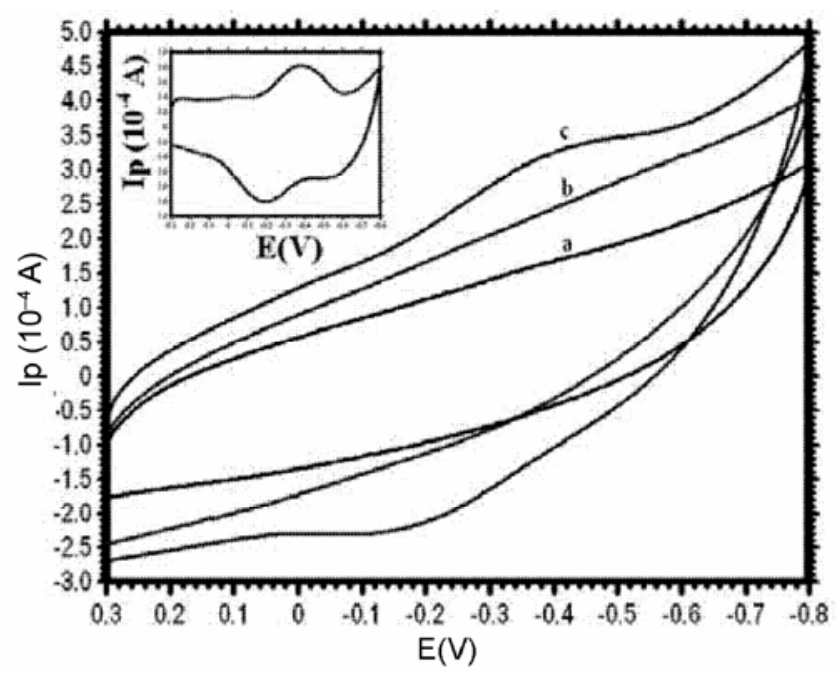

Figure 4. Cyclic voltammograms of (a), bare CILE; (b), $\mathrm{De} / \mathrm{CILE}$; (c), De/Hb/CILE at the scan rate of $100 \mathrm{mV} / \mathrm{s}$ in pH 7.0 PBS (inset: the background-subtracted cyclic voltammogram of $\mathrm{De} / \mathrm{Hb} / \mathrm{CILE}$ using data presented in curve b).

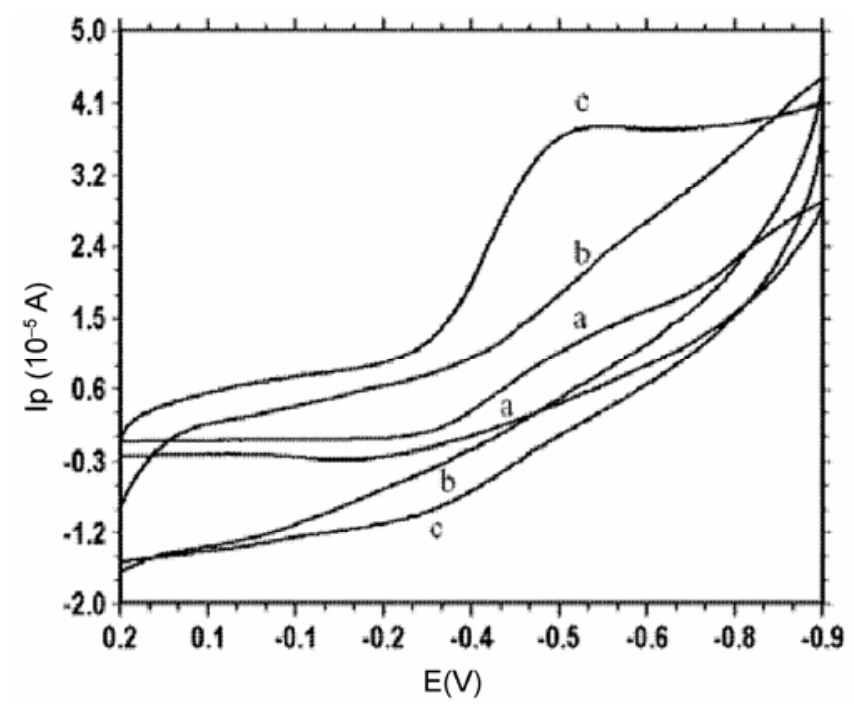

Figure 5. Cyclic voltammograms of (a), bare CPE; (b), $\mathrm{De} / \mathrm{CPE}$; (c), $\mathrm{De} / \mathrm{Hb} / \mathrm{CPE}$ at the scan rate of $100 \mathrm{mV} / \mathrm{s}$ in $\mathrm{pH}$ 7.0 PBS. day's constant, A is the area of electrode. From the experimental results the average surface concentration of electroactive $\mathrm{Hb}\left(\Gamma^{*}\right)$ on the electrode surface was estimated to be $2.64 \times 10^{-9} \mathrm{~mol} / \mathrm{cm}^{2}$. Because $\mathrm{Hb}$ was cast onto the surface of CILE and the total amount of $\mathrm{Hb}$ in the film was calculated as $2.47 \times 10^{-8} \mathrm{~mol} / \mathrm{cm}^{2}$. So the electroactive $\mathrm{Hb}$ on the electrode surface accounted for $10.7 \%$ of the total amount of $\mathrm{Hb}$ in the film, which was larger than the reported values of $1.3 \%$ (ref. 38 ) and $2.0 \% .^{31}$ The results indicated that only the $\mathrm{Hb}$ molecules close to the electrode surface could exchange the electron with the CILE.

The relationship of the peak potentials with scan rate was further constructed, which could be used for the calculation of the electrochemical parameters. According to the Laviron's equations: ${ }^{39}$

$$
\begin{aligned}
& E p c= E^{0^{\prime}}-\frac{2 \cdot 3 R T}{\alpha n F} \log v \\
& E p c=E^{0^{\prime}}-\frac{2 \cdot 3 R T}{(1-\alpha) n F} \log v \\
& \log k_{s}=\alpha \log (1-\alpha)+(1-\alpha) \log \alpha \\
& \quad-\log \frac{R T}{n F v}-\frac{(1-\alpha) \alpha F n \Delta E p}{2 \cdot 3 R T},
\end{aligned}
$$

where $\alpha$ is the electron transfer coefficient, $n$ is the electron transfer number, $k_{s}$ is the apparent heterogeneous electron transfer rate constant, $v$ is the scan rate, $E^{0,}$ is the apparent formal potential and $F$ is the Faraday's constant.

A linear relationship between the $E p$ with the $\log v$ was established and two straight lines were obtained with the results as shown in figure 7 . The linear regression equations were calculated as $\operatorname{Epa}(V)=$ $0.047 \log v(\mathrm{mV} / \mathrm{s})-0.085 \quad(n=7, \quad \gamma=0.993) \quad$ and $\operatorname{Epc}(V)=-0.076 \log v(\mathrm{mV} / \mathrm{s})-0.54(n=7, \gamma=0.992)$. According to the (2) and (3) the electron transfer coefficient $(\alpha)$ and the electron transfer number $(n)$ could be calculated and the result was 0.463 and $0 \cdot 89$, respectively. Based on the (4) the value of $k_{s}$ was further calculated from the relationship of $\Delta E \mathrm{p}$ with $\log v$ and the result was $0.428 \mathrm{~s}^{-1}$.

The effect of buffer $\mathrm{pH}$ on the direct electrochemistry of $\mathrm{Hb}$ was also examined. It is well-known that most of the heme proteins exhibit a $\mathrm{pH}$-dependent conformational equilibrium and the $\mathrm{pH}$ value of the 
buffer solution influences the electrochemical reactions of the heme proteins. In the $\mathrm{pH}$ range from 5.5 to 9.0 stable and well-defined cyclic voltammograms could be obtained. The apparent formal potential $\left(E^{0 \prime}\right)$ of $\mathrm{Hb}$ showed a negatively shift with the increase of buffer solution. A good linear relationship of $E^{0 \prime}$ and $\mathrm{pH}$ value was obtained with the linear regression equation as $E^{0 \prime}(V)=-0.0447 \mathrm{pH}+0.0076$ $(n=8, \gamma=0.992)$. The slope value was $-44.7 \mathrm{mV} /$ $\mathrm{pH}$, which was reasonably close to the theoretical value of $-56.0 \mathrm{mV} / \mathrm{pH}$ at $20^{\circ} \mathrm{C}$ for a one protoncoupled single electron transfer process. So the electrode process can be represented as $\mathrm{Hb} \mathrm{Fe}(\mathrm{III})+$ $\mathrm{H}^{+}+\mathrm{e} \rightleftharpoons \mathrm{Hb} \mathrm{Fe}(\mathrm{II}){ }^{40}$

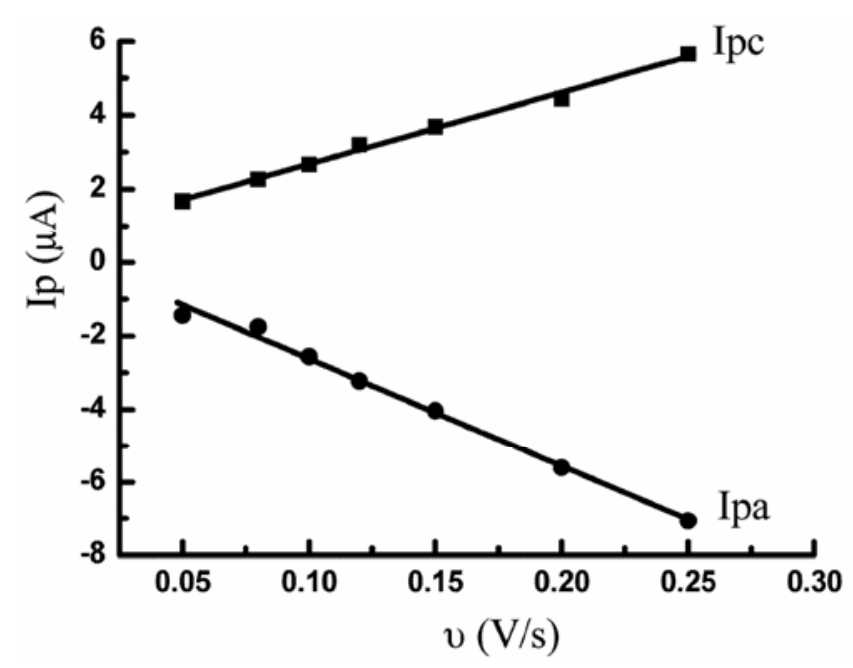

Figure 6. Linear relationship of redox peak current (Ip) versus scan rate $(v)$ in $\mathrm{pH} 7 \cdot 0 \mathrm{PBS}$.

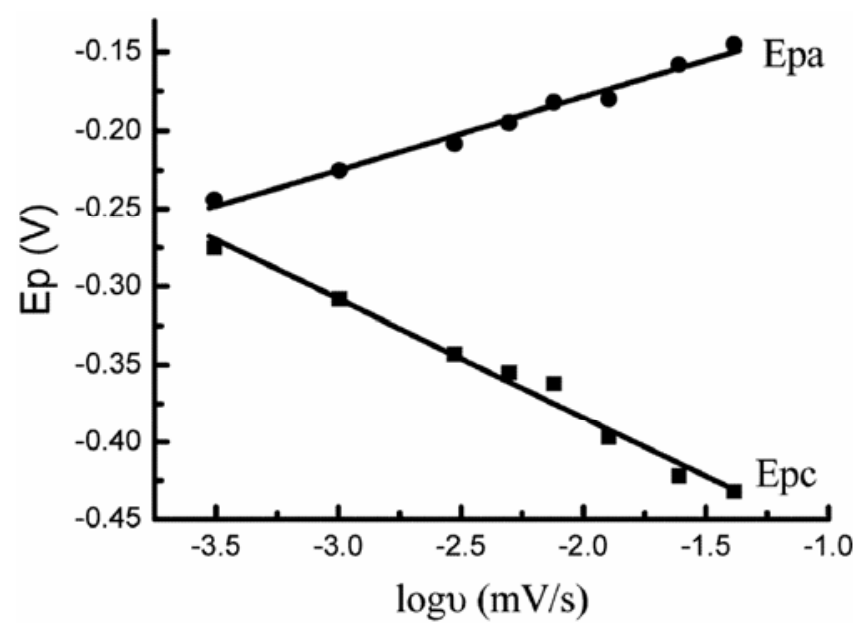

Figure 7. Linear relationship of the anodic (Epa) and cathodic (Epc) peak potential against $\log v$.

\subsection{Electrocatalysis of $\mathrm{De} / \mathrm{Hb} / \mathrm{CILE}$ to $\mathrm{H}_{2} \mathrm{O}_{2}$}

Electrocatalytic reduction of $\mathrm{H}_{2} \mathrm{O}_{2}$ on $\mathrm{De} / \mathrm{Hb} / \mathrm{CILE}$ was investigated by cyclic voltammetry. With the addition of $\mathrm{H}_{2} \mathrm{O}_{2}$ into a pH 7.0 PBS in the electrochemical cell, an obvious increase of the cathodic peak current was observed with the decrease of the anodic peak current, which was the characteristic of an electrochemically catalytic reaction. The catalytic peak potential was located at $-270 \mathrm{mV}$ and the cathodic peak current increased with the increase of $\mathrm{H}_{2} \mathrm{O}_{2}$ concentration. While no electrochemical signals could be observed on the bare CILE and De/ CILE in the same potential range. A linear relationship between the catalytic peak current and $\mathrm{H}_{2} \mathrm{O}_{2}$ concentration was obtained in the range of $4.0 \times 10^{-6}$ to $1.5 \times 10^{-5} \mathrm{~mol} / \mathrm{L}$ with the linear regression equation as $\operatorname{Iss}(\mu \mathrm{A})=0.013 \mathrm{C}(\mu \mathrm{mol} / \mathrm{L})+0.355 \quad(n=6, \quad \gamma=0.993)$ and the detection limit was $1.0 \times 10^{-7} \mathrm{~mol} / \mathrm{L}(3 \sigma)$.

The apparent Michaelis-Menten constant $\left(K_{\mathrm{M}}{ }^{\text {app }}\right)$, which provided to be an indication of the enzymesubstrate kinetics, was calculated from the electrochemical version of the Lineweaver-Burk equation. $^{41}$

$$
\frac{1}{I_{S S}}=\frac{1}{I_{\max }}+\frac{K_{M}^{\mathrm{app}}}{I_{\max } C}
$$

where $I_{\mathrm{ss}}$ is the steady current after the addition of substrate, $C$ is the bulk concentration of the substrate, and $I_{\max }$ is the maximum current measured under saturated substrate condition.

By analysis of the steady-state current and the $\mathrm{H}_{2} \mathrm{O}_{2}$ concentration, the apparent Michaelis-Menten constant could be calculated as $0 \cdot 17 \mu \mathrm{mol} / \mathrm{L}$, which was lower than that of some previous reports. ${ }^{42,43}$ Thus, the $\mathrm{Hb}$ immobilized in $\mathrm{De}$ film had good affinity to $\mathrm{H}_{2} \mathrm{O}_{2}$ and showed high electrocatalytic efficiency.

The $\mathrm{De} / \mathrm{Hb} / \mathrm{CILE}$ showed good stability. The $\mathrm{Hb}$ modified electrode was stored in a refrigerator at $4^{\circ} \mathrm{C}$ for 15 days with the peak current decreased for $3 \%$ and 30 days with the peak current decreased for $8 \%$, The results showed good storage stability for the $\mathrm{De} / \mathrm{Hb} / \mathrm{CILE}$.

\subsection{Electrochemical characteristics of modified electrodes}

Electrochemical impedance spectroscopy (EIS) is a valuable method to give information on the imped- 

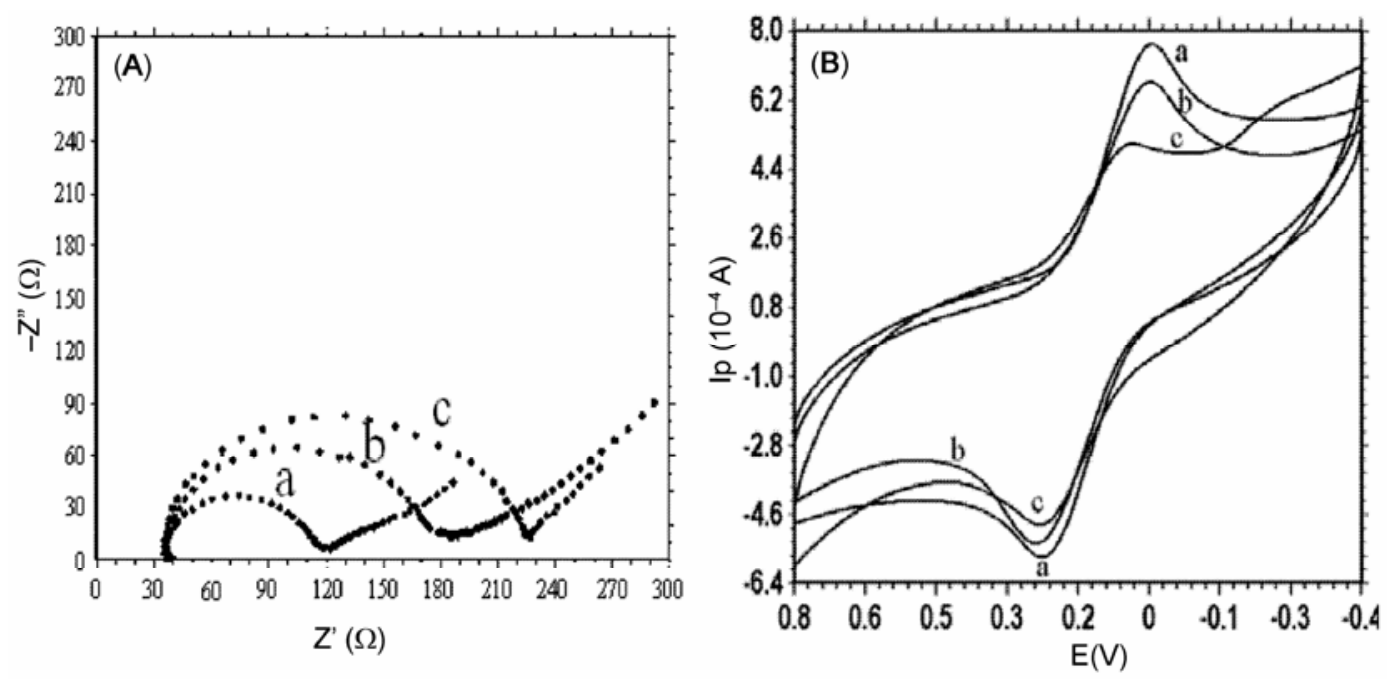

Figure 8. (A) Electrochemical impedance spectroscopy for curve (a), bare CILE; curve (b), $\mathrm{De} / \mathrm{CILE}$; (c), De/Hb/CILE in the presence of $10.0 \mathrm{mmol} / \mathrm{L}\left[\mathrm{Fe}(\mathrm{CN})_{6}\right]^{3-/ 4-}$ and $0.1 \mathrm{~mol} / \mathrm{L} \mathrm{KCl}$ with the frequency range from $10^{5}$ to $0.1 \mathrm{~Hz}$. (B) Cyclic voltammograms of curve (a), bare CILE; curve (b), De/CILE; curve (c), De/Hb/CILE in $0.1 \mathrm{~mol} / \mathrm{L} \mathrm{KCl}$ solution containing $1.0 \mathrm{mmol} / \mathrm{L}\left[\mathrm{Fe}(\mathrm{CN})_{6}\right]^{3-}$ with the scan rate of $100 \mathrm{mV} / \mathrm{s}$.

ance changes of modified electrode and the semicircle diameter of EIS equals to the electron transfer resistance (Ret). By using $1.0 \times 10^{-4} \mathrm{~mol} / \mathrm{L}$ $\mathrm{Fe}(\mathrm{CN})_{6}^{33-/ 4}$ solution as the redox probe with the frequencies sweep from $10^{5}$ to $0 \cdot 1 \mathrm{~Hz}$, the EIS of different electrodes were shown in figure $8(\mathrm{~A})$. The Ret of bare CILE was estimated to be $72.0 \Omega$ (curve a), which was due to the presence of highly conductive RTILs in the mixture with graphite powder. The Ret value of De/CILE was got as 108.2 $\Omega$ (curve b), indicating the presence of De film could hinder the electron transfer of $\mathrm{Fe}(\mathrm{CN})_{6}^{33-/ 4-}$. However, the Ret value of $\mathrm{De} / \mathrm{Hb} / \mathrm{CILE}$ was further increased to $134.5 \Omega$ (curve c), which was larger than that of bare CILE and De/CILE. This might be due to the presence of $\mathrm{Hb}$ in the film, which further hindered the transfer of electrons. Cyclic voltammograms of different electrodes were further recorded in $\mathrm{Fe}(\mathrm{CN})_{6}^{3-}$ solution with the results shown in figure 8(B). On CILE a pair of well-defined quasireversible redox peaks were observed (curve a). While on the De/CILE (curve b) the redox peak current decreased, which was due to the presence of De on the electrode surface. On the De/Hb/CILE (curve c) the redox peak current was further decreased, indicating the presence of $\mathrm{Hb}$ molecules in the De film hindered the electron transfer rate. The results were in consistent with that of EIS, which indicated the successful fabrication of the $\mathrm{De}$ and $\mathrm{Hb}$ modified electrode.

\section{Conclusions}

In this paper, an ionic liquid $\mathrm{BMIMPF}_{6}$ modified carbon paste electrode (CILE) was constructed and $\mathrm{Hb}$ was immobilized on the surface of CILE with the help of De film by layer-to-layer casting method. The presence of De film provided a biocompatible microenvironment for the $\mathrm{Hb}$. UV-Vis and FT-IR spectra indicated that $\mathrm{Hb}$ retained its secondary structure in the film. The CILE provided a biocompatible interface with high conductivity and excellent electron transfer efficiency. The $\mathrm{De} / \mathrm{Hb}$ film modified CILE exhibited good electrochemical catalytic reduction of $\mathrm{H}_{2} \mathrm{O}_{2}$, which could be further used for the construction of $\mathrm{H}_{2} \mathrm{O}_{2}$ biosensor.

\section{Acknowledgement}

We are grateful to the Shandong Province Natural Science Foundation (ZR2009BM022) for financial support.

\section{References}

1. Xiao Y, Ju H X and Chen H Y 2000 Anal. Biochem. 27822

2. Gu H Y, Yu A M and Chen H Y 2001 J. Electroanal. Chem. 516119

3. Hu N and Rusling J F 1997 Langmuir 134119

4. Sun $\mathrm{H}, \mathrm{Hu} \mathrm{N}$ and $\mathrm{Ma} \mathrm{H} 2000$ Electroanalysis 12 1064 
5. Shen L, Huang R and Hu N 2002 Talanta 561131

6. Sun W, Li X Q, Zhai Z Q and Jiao K 2008 Electroanalysis 202649

7. Brown K R, Fox A P and Natan M J $1996 \mathrm{~J}$. Am. Chem. Soc. 1181154

8. Sun W, Wang D D, Li G C, Zhai Z Q, Zhao R J and Jiao K 2008 Electrochim. Acta 538217

9. Buzzeo M C, Hardace C and Compton R G 2004 Anal. Chem. 764583

10. Sun W, Li Y Z, Duan Y Y and Jiao K 2008 Biosensor Bioelectron. 24983

11. He P, Liu H, Li Z and Li J H 2005 J. Electrochem. Soc. 152 E146

12. Hultgren V M, Mariotti A W A, Bond A M and Wedd A G 2002 Anal. Chem. 743151

13. Sun W, Wang D D, Gao R F and Jiao K 2007 Electrochem. Commun. 91159

14. Boxall D L and Osteryoung R A 2002 J. Electrochem. Soc. 149 E185

15. Stathatos E and Lianos P 2003 Chem. Mater. 15 1825

16. Buijsman R C, Vuuren E Van and Sterrenburg J G 2001 Org. Lett. 33785

17. Singer R D and Scammells P 2001 Tetrahedron Lett. 426831

18. Kim K S, Demberelnyamba D and Lee H 2004 Langmuir 20556

19. Zhou Y, Schattka J H and Antonietti M 2004 Nano. Lett. 4477

20. Bosmann A, Datserish L, Jess A, Lauter A E and Wasserscheid P 2001 Chem. Commun. 2494

21. Sun W, Gao R F and Jiao K 2007 Chinese J. Anal. Chem. 351813

22. Liu H T, He P and Li Z Y 2005 Electrochem. Commun. 71357

23. Buzzeo M C, Evans R G and Compton R G 2004 Chem. Phys. Chem. 51106

24. Endres F 2004 Zeitschtift fur physikalische Chemie 218255
25. Rozniecka E, Shul G, Sirieix-Plenet J, Gaiuon L and Opallo M 2005 Electrochem. Commun. 7299

26. Rozniecka E, Niedzidka J, Sirieix-Plenet J, Gaiuon L, Murphy M A, Marken F and Opallo M 2006 J. Electroanal. Chem. $\mathbf{5 8 7} 133$

27. Shul G, Sirieix-Plenet J, Gaiuon L and Opallo M 2006 Electrochem. Commun. 81111

28. Yu P, Lin Y Q, Xiang L, Lei S, Zhang J and Mao L Q 2005 Langmuir 219000

29. Li C M, Zang J F, Zhan D P, Chen W, Sun L Q, Teo A L, Chua Y T, Lee V S and Moochhala S M 2006 Electroanalysis 18713

30. Sun W, Yang M X, Gao R F and Jiao K 2007 Electroanalysis 191597

31. Lu X B, Hu J Q, Yao X, Wang Z P and Li J H 2006 Biomacromolecules 7975

32. Sun W, Gao R F and Jiao K 2007 J. Phys. Chem. B111 4560

33. Sun W, Zhai Z Q, Wang D D, Liu S F and Jiao K 2009 Bioelectrochemistry 74295

34. Sun W, Gao R F and Jiao K 2007 Electroanalysis 19 1368

35. Rusling J F and Nassar A E F $1993 \mathrm{~J}$. Am. Chem. Soc. 11511891

36. Rusling J F and Kumonsinski T F 1992 Int. Instrum. Comput. 10139

37. Nassar A E F and Rusling J F $1996 \mathrm{~J}$. Am. Chem. Soc. 1183043

38. Gao R F, Shangguan X D, Qiao G J and Zheng J B 2008 Electroanalysis 202537

39. Laviron E 1979 J. Electroanal. Chem. 10119

40. Fan C H, Zhuang Y, Li G X, Zhu J Q and Zhu D X 2000 Electroanalysis 141156

41. Kamin R A and Wilson G S 1980 Anal. Chem. 52 1198

42. Wang H Y, Guan R, Fan C H, Zhu D X and Li G X 2002 Sensor Actuators B84 214

43. Li J, Tan S N and Ge H 1996 Anal. Chim. Acta 335 137 